http://jmscr.igmpublication.org/home/ ISSN (e)-2347-176x ISSN (p) 2455-0450 crossref DOI: https://dx.doi.org/10.18535/jmscr/v8i1.69

\author{
Dournal Of Medical Science And Clinical Research \\ IGM Publication \\ An official Publication of IGM Publication
}

\title{
Epedemiological and Clinical Profile of Hemodialysis Patients in a Tertiary Care Centre
}

\author{
Authors \\ Dr Padmakumar $\mathbf{C}^{1}$, Dr Arun Varghese $\mathbf{T}^{2}$
}

${ }^{1}$ Asst Professor of Nephrology, Kanyakumari Government Medical College, Kanyakumari District 629201

${ }^{2}$ Asst Professor of Nephrology, Kanyakumari Government Medical College, Kanyakumari District 629201

*Corresponding Author

Dr Arun Varghese T

Asst professor of Nephrology, Kanyakumari Government Medical College, Kanyakumari District 629201

\begin{abstract}
Data regarding epidemiolocal and clinical profile of patients in a haemodialysis unit in South India is scarce. This study was conducted to describe the epidemiological and clinical profiles of End Stage Renal Disease (ESRD) patients undergoing haemodialysis in Kanyakumari Government Medical College Hospital. This was a cross-sectional study in which all ESRD patients on haemodialysis were evaluated. Of the 76 patients (82.9\%) were males. Diabetes was the most common cause of ESRD in34 (77.4\%) patients. Seventy-four (97.4\%) patients had emergency dialysis initiation through central venous cannulation. Interdialytic weight gain was lower [1.76 kilograms (SD-0.76)] and dialysis vintage was longer [29.24 months (SD-15.93)] in patients receiving thrice weekly haemodialysis.

Keywords: epidemiological profile; clinical profile; haemodialysis.
\end{abstract}

\section{Introduction}

Chronic kidney disease (CKD) has been defined as a decrease in estimated glomerular filtration rate (eGFR) to a level of $<60 \mathrm{~mL} / \mathrm{min} / 1.73 \mathrm{~m} 2$ or evidence of albumin excretion or both over a three-month period with or without structural changes. An eGFR level of less than 15 $\mathrm{mL} / \mathrm{min} / 1.73 \mathrm{~m} 2$ was defined as the final stage of CKD, called end-stage renal disease (ESRD). ESRD refers to the kidneys' inability to maintain homeostasis and requires patients to rely on a renal replacement therapy (RRT). Hemodialysis continues to be the predominant RRT modality in our country.

The mean global prevalence of CKD based on the study by Hill et al. was $13.4 \%$ for the 44 population studies that measured prevalence by all 5 stage and $10.6 \%$ for the sixty-eight population studies measuring stages 3 to $5^{[1]}$ According to Lijie et al age, diabetes mellitus (DM) and ferritin were factors associated with increased risk of allcause mortality, whereas BMI, haemoglobin, albumin were associated with reduced risk of all causes mortality ${ }^{[2]}$. There are very few studies evaluating the profile of haemodialysis patients in south India.

\section{Methods}

This prospective cross-sectional study was conducted in the Haemodialysis unit in Kanyakumari Government Medical College at Kanyakumari District, Tamilnadu, India. This is a 
large Haemodialysis unit in which treatment is provided free of cost to the patients under Government Chief Minister's health insurance scheme (CMCHIS). This unit caters to the needs of people from three districts including Kanyakumari, Tirunelveli and Tuticorin. Patients undergo either twice or thrice weekly haemodialysis each session lasting for four hours depending on the clinical status of the patient. Data was collected from patients from September 2018 to November 2018.Patients with End Stage Renal Disease on Maintenance Haemodialysis were included in the study. Patients with incomplete Medical data were excluded from the study.

The Epidemiological profile evaluated include age, gender, geographical profile including village taluk district distance from haemodialysis unit, educational status, marital status, occupational status of the patient, financial status and caretaker

The Clinical profile evaluated includes seropositive status, basic disease/aetiology of ESRD, haemodialysis vintage, previous centre, access evaluation including present and previous arteriovenous fistula, previous internal jugular vein cannulation, arteriovenous failure, haemodialysis frequency/week, number of antihypertensives requirement, haemodialysis complications, hospitalisation history, and interdialytic weight gain

The Laboratory profiles included haemoglobin, total count, platelet count, potassium, alanine transaminase, aspartate transaminase, alkaline phosphatase, direct and indirect bilirubin, sodium, potassium, protein, albumin, blood sugar, uric acid and cholesterol. The blood pressures, heights and weights of patients were also recorded Data were analysed statistically using SPSS version 20.0

The results were presented as numbers and percentages, means and standard deviations, and medians. For the analytical tests, we used the chi square test, dependent t-test, Mann-Whitney test, and ANOVA. $\mathrm{P}$ values of $<0.05$ were considered significant. The protocol of this study was approved by the institute ethical committee. Informed consent to participate was obtained in the study

\section{Aim}

- To determine the etiological and clinical profile in haemodialysis patients

- To correlate the frequency of haemodialysis with the clinical profile

\section{Results}

There were seventy-six haemodialysis patients. The mean age of patients was 48.1 years (SD 14.0). Sixty-three patients $(82.9 \%)$ were males (table 1a). Seven patients $(9.2 \%)$ were graduates. Majority of patients $(48.7 \%)$ had not completed primary school (table $1 \mathrm{~b})$. Ten patients $(13.2 \%)$ were unmarried, sixty three patients $(82.9 \%)$ were married and three patients $(3.9 \%)$ were living alone (table 1c). Eleven patients (14.5\%) were employed and sixty five patients $(85.5 \%)$ were unemployed (table 1d).

Analysing the aetiology of chronic Kidney disease thirty-four (44.7\%) patients had CKD due to diabetes mellites. In twenty-five (32.9\%) CKD was due to hypertension and seventeen patients (22.4\%) had CKD due to other aetiology (table $1 \mathrm{e})$. Eight patients $(10.5 \%)$ had previous arterio venous fistula failure (table 1f). Seventy-four patients (97.4\%) had previous emergency dialysis initiated through internal jugular vein cannulation. Only two patients $(2.6 \%)$ had pre-emptive AV fistula creation and did not need IJV cannulation (table 1g). Three patients (3.9\%) did not need antihypertensives. Thirty-two patients (42.1\%) needed two antihypertensive and thirty-six patients $(47.4 \%)$ needed three antihypertensive respectively (table 1f). Twenty-two patients (28.9\%) developed hypotension during dialysis in the preceding four weeks (table 1g). Twentyseven patients $(35.5 \%)$ required hospitalisation in the preceding eight weeks (table $1 \mathrm{~h}$ ). 
Fifty one patients $(67.1 \%)$ were receiving twice weekly and twenty five patients (32.9\%) were receiving thrice weekly haemodialysis(table $2 a$ ). There was no significant difference between patients receiving twice and thrice weekly haemodialysis in comparing the rates of previous AVF creation, previous IJV cannulation, antihypertensives requirement, hemodialysis complications and hospitalisation [p>0.05] (table $2 \mathrm{~b}, 2 \mathrm{c}, 2 \mathrm{~d}, 2 \mathrm{e}, 2 \mathrm{f})$. The Haemodialysis vintage was longer in patients receiving thrive weekly haemodialysis with a mean of 29.24 months [p=0.02] (table $2 \mathrm{~g}$ ). The interdialytic weight gain was lesser in patients receiving thrice weekly Haemodialysis with a mean of $1.75 \mathrm{~kg}[\mathrm{p}<0.0001)$ (table 2h). The platelet counts and sodium values were higher in patients receiving thrice weekly haemodialysis $[\mathrm{p}<0.05]$. There was no significant difference in the other laboratory parameters while comparing patients on twice and thrice weekly hemodialysis 9 table $2 \mathrm{i}$ )

Epedemiological and Clinical Profile in Hemodialysis Patients

Table 1a: Gender

\begin{tabular}{|l|c|c|}
\hline & Frequency & Percent \\
\hline MALE & 63 & 82.9 \\
FEMALE & 13 & 17.1 \\
Total & 76 & 100.0 \\
\hline
\end{tabular}

Table 1b: Education

\begin{tabular}{|l|c|c|}
\hline & Frequency & Percent \\
\hline UPTO PRIMARY SCHOOL & 37 & 48.7 \\
UPTO HIGHER SECONDARY & 32 & 42.1 \\
SCHOOL & 7 & 9.2 \\
GRADUATE & 76 & 100.0 \\
Total & \\
\hline
\end{tabular}

Table 1c: Marital Status

\begin{tabular}{|l|c|c|}
\hline & Frequency & Percent \\
\hline MARRIED & 63 & 82.9 \\
UNMARRIED & 10 & 13.2 \\
LIVING ALONE & 3 & 3.9 \\
Total & 76 & 100.0 \\
\hline
\end{tabular}

Table 1d: Occupational Status

\begin{tabular}{|l|c|c|}
\hline & Frequency & Percent \\
\hline YES & 11 & 14.5 \\
NO & 65 & 85.5 \\
Total & 76 & 100.0 \\
\hline
\end{tabular}

Table 1e: Basic Disease

\begin{tabular}{|l|c|c|}
\hline & Frequency & Percent \\
\hline DIABETES MELLITES & 34 & 44.7 \\
HYPERTENSION & 25 & 32.9 \\
OTHERS & 17 & 22.4 \\
Total & 76 & 100.0 \\
\hline
\end{tabular}

Table 1f: Previous AVF

\begin{tabular}{|l|c|c|}
\hline & Frequency & Percent \\
\hline YES & 8 & 10.5 \\
NO & 68 & 89.5 \\
Total & 76 & 100.0 \\
\hline
\end{tabular}

Table 1g: Previous IJV

\begin{tabular}{|l|c|c|}
\hline & Frequency & Percent \\
\hline YES & 74 & 97.4 \\
NO & 2 & 2.6 \\
Total & 76 & 100.0 \\
\hline
\end{tabular}

Table 1h: Antihypertensives

\begin{tabular}{|l|c|c|}
\hline & Frequency & Percent \\
\hline NIL & 3 & 3.9 \\
ONE & 32 & 42.1 \\
TWO & 36 & 47.4 \\
THREE & 4 & 5.3 \\
FOUR AND ABOVE & 1 & 1.3 \\
Total & 76 & 100.0 \\
\hline
\end{tabular}

Table 1i: Hemodialysis Complications

\begin{tabular}{|l|c|c|}
\hline & Frequency & Percent \\
\hline NIL & 29 & 38.2 \\
HYPOTENSION & 22 & 28.9 \\
ITCHING/FEVER & 21 & 27.6 \\
OTHER & 4 & 5.3 \\
Total & 76 & 100.0 \\
\hline
\end{tabular}

Table 1j:Hospitalisation

\begin{tabular}{|l|c|c|}
\hline & Frequency & Percent \\
\hline NIL & 48 & 63.2 \\
ONCE & 27 & 35.5 \\
TWICE & 1 & 1.3 \\
Total & 76 & 100.0 \\
\hline
\end{tabular}


Correlation of Frequency of Hemodialysis with the Clinical Profile

Table 2a: Frequency

\begin{tabular}{|ll|c|c|}
\hline & & Frequency & Percent \\
\hline Valid & TWICE & 51 & 67.1 \\
& WEEKLY & & \\
& THRICE & 25 & 32.9 \\
WEEKLY & & \\
& Total & 76 & 100.0 \\
\hline
\end{tabular}

Table 2b: Previous AVF

\begin{tabular}{|c|c|c|c|c|c|}
\hline & \multicolumn{2}{|c|}{ PREVIOUS AVF } & \multirow{2}{*}{ Total } & \multirow{2}{*}{$P$ value } \\
\hline & & YES & $\mathrm{NO}$ & & \\
\hline \multirow{2}{*}{ Frequency } & 2.00 & 5 & 46 & 51 & \multirow{3}{*}{0.769} \\
\hline & 3.00 & 3 & 22 & 25 & \\
\hline \multicolumn{2}{|l|}{ Total } & 8 & 68 & 76 & \\
\hline
\end{tabular}

Table 2c: Previous IJV

\begin{tabular}{|c|c|c|c|c|c|}
\hline & \multicolumn{2}{|c|}{ PREVIOUS IJV } & \multirow{2}{*}{ Total } & \multirow{2}{*}{$P$ value } \\
\hline & & YES & $\mathrm{NO}$ & & \\
\hline \multirow{2}{*}{ Frequency } & 2.00 & 50 & 1 & 51 & \multirow{3}{*}{0.602} \\
\hline & 3.00 & 24 & 1 & 25 & \\
\hline \multicolumn{2}{|l|}{ Total } & 74 & 2 & 76 & \\
\hline
\end{tabular}

Table 2d: Antihypertensives Requirement

\begin{tabular}{|l|c|c|c|c|c|c|c|c|}
\hline \multicolumn{2}{|c|}{} & \multicolumn{9}{|c|}{ NUMBER OF ANTI HYPERTENSIVES } & \multirow{2}{*}{ Total } & \multirow{2}{*}{ P value } \\
\cline { 3 - 9 } & NIL & ONE & TWO & THREE & $\begin{array}{c}\text { FOUR } \\
\text { OR } \\
\text { MORE }\end{array}$ & \multirow{2}{*}{0.429} \\
\cline { 1 - 9 } Frequency & 2.00 & 3 & 22 & 23 & 3 & 0 & 51 & \\
\cline { 2 - 9 } & 3.00 & 0 & 10 & 13 & 1 & 1 & 25 & \\
\hline \multicolumn{2}{|l|}{ Total } & 3 & 32 & 36 & 4 & 1 & & \\
\hline
\end{tabular}

Table 2e: Hemodialysis Complications

\begin{tabular}{|c|c|c|c|c|c|c|c|}
\hline & \multicolumn{4}{|c|}{ HEMODIALYSIS COMPLICATIONS } & \multirow{2}{*}{ Total } & \multirow{2}{*}{$\mathrm{P}$ value } \\
\hline & & NIL & HYPOTENSION & ITCHING/FEVER & OTHERS & & \\
\hline \multirow{2}{*}{ Frequency } & 2.00 & 18 & 17 & 14 & 2 & 51 & \multirow{3}{*}{0.594} \\
\hline & 3.00 & 11 & 5 & 7 & 2 & 25 & \\
\hline \multicolumn{2}{|l|}{ Total } & 29 & 22 & 21 & 4 & 76 & \\
\hline
\end{tabular}

Table 2f: Hospitalisation

\begin{tabular}{|c|c|c|c|c|c|c|}
\hline & & \multicolumn{3}{|c|}{ HOSPITALISATION } & \multirow{2}{*}{ Total } & \multirow{2}{*}{$\mathrm{P}$ value } \\
\hline & & NIL & ONCE & TWICE & & \\
\hline \multirow{2}{*}{ Frequency } & 2.00 & 32 & 18 & 1 & 51 & \multirow{3}{*}{0.78} \\
\hline & 3.00 & 16 & 9 & 0 & 25 & \\
\hline \multicolumn{2}{|l|}{ Total } & 48 & 27 & 1 & 76 & \\
\hline
\end{tabular}

Table 2g: Hemodialysis Vintage

\begin{tabular}{|l|l|c|c|c|c|}
\hline \multicolumn{2}{|l|}{ Frequency } & $\mathrm{N}$ & Mean & Std. Deviation & P value \\
\hline \multicolumn{2}{|c|}{2.00} & 51 & 21.49 & 11.94 & \\
\cline { 2 - 6 } & 3.00 & 25 & 29.24 & 15.93 & 0.02 \\
\hline
\end{tabular}


Table 2h: Inter Dialytic Weight Gain

\begin{tabular}{|c|c|c|c|c|}
\hline Frequency & $\mathrm{N}$ & Mean & Std. Deviation & $\mathrm{P}$ value \\
\hline 2.00 & 51 & 3.00 & 1.25 & \multirow{2}{*}{$<0.0001$} \\
\hline 3.00 & 25 & 1.75 & 0.76 & \\
\hline
\end{tabular}

Table 2i: Laboratory parameters and frequency of Hemodialysis

\begin{tabular}{|c|c|c|c|c|c|}
\hline \multicolumn{2}{|l|}{ Frequency } & $\mathrm{N}$ & Mean & $\begin{array}{c}\text { Std. } \\
\text { Deviation }\end{array}$ & $P$ value \\
\hline \multirow[t]{2}{*}{ HEMOGLOBIN } & 2.00 & 51 & 7.45 & 1.40 & \multirow[t]{2}{*}{0.88} \\
\hline & 3.00 & 25 & 7.51 & 1.66 & \\
\hline \multirow[t]{2}{*}{ TOTAL COUNT } & 2.00 & 51 & 6607.84 & 1717.65 & \multirow[t]{2}{*}{0.366} \\
\hline & 3.00 & 25 & 7052.00 & 2490.33 & \\
\hline \multirow[t]{2}{*}{ PLATELET } & 2.00 & 51 & 1.76 & 0.48 & \multirow[t]{2}{*}{0.017} \\
\hline & 3.00 & 25 & 2.06 & 0.55 & \\
\hline \multirow[t]{2}{*}{ SUGAR } & 2.00 & 51 & 97.20 & 50.24 & \multirow[t]{2}{*}{0.707} \\
\hline & 3.00 & 25 & 93.28 & 17.40 & \\
\hline \multirow[t]{2}{*}{ UREA } & 2.00 & 51 & 99.94 & 24.92 & \multirow[t]{2}{*}{0.135} \\
\hline & 3.00 & 25 & 116.88 & 72.17 & \\
\hline \multirow[t]{2}{*}{ CREATININE } & 2.00 & 51 & 9.10 & 14.43 & \multirow[t]{2}{*}{0.327} \\
\hline & 3.00 & 25 & 6.24 & 1.82 & \\
\hline \multirow[t]{2}{*}{ SGOT } & 2.00 & 51 & 24.22 & 9.16 & \multirow[t]{2}{*}{0.841} \\
\hline & 3.00 & 25 & 24.64 & 7.45 & \\
\hline \multirow[t]{2}{*}{ SGPT } & 2.00 & 51 & 29.45 & 24.91 & \multirow[t]{2}{*}{0.532} \\
\hline & 3.00 & 25 & 26.20 & 9.60 & \\
\hline \multirow{2}{*}{$\begin{array}{l}\text { ALKALINE } \\
\text { PHOSPHATASE }\end{array}$} & 2.00 & 51 & 78.82 & 15.70 & \multirow[t]{2}{*}{0.211} \\
\hline & 3.00 & 25 & 83.64 & 15.46 & \\
\hline \multirow[t]{2}{*}{ BILIRUBIN D } & 2.00 & 51 & 0.84 & 0.52 & \multirow[t]{2}{*}{0.373} \\
\hline & 3.00 & 25 & 0.74 & 0.11 & \\
\hline \multirow[t]{2}{*}{ BILIRUBIN } & 2.00 & 51 & 0.29 & 0.08 & \multirow[t]{2}{*}{0.277} \\
\hline & 3.00 & 25 & 0.27 & 0.07 & \\
\hline \multirow[t]{2}{*}{ SODIUM } & 2.00 & 51 & 132.61 & 5.98 & \multirow[t]{2}{*}{0.007} \\
\hline & 3.00 & 25 & 136.76 & 6.53 & \\
\hline \multirow[t]{2}{*}{ POTASSIUM } & 2.00 & 51 & 3.98 & 0.74 & \multirow[t]{2}{*}{0.073} \\
\hline & 3.00 & 25 & 3.68 & 0.49 & \\
\hline \multirow[t]{2}{*}{ PROTEIN } & 2.00 & 51 & 6.61 & 0.62 & \multirow[t]{2}{*}{0.637} \\
\hline & 3.00 & 25 & 6.67 & 0.37 & \\
\hline \multirow[t]{2}{*}{ ALBUMIN } & 2.00 & 51 & 3.69 & 0.40 & \multirow[t]{2}{*}{0.068} \\
\hline & 3.00 & 25 & 3.91 & 0.63 & \\
\hline
\end{tabular}

\section{Discussion}

The epidemiological profile was similar to the studies previously published from India. The mean age of participants in our study was comparable to that of the study by Vijayalakshmi et al (48.1 years; SD 14 vs 53.5 years; SD 14.5). ${ }^{[3]}$ The main aetiology of ESRD in our study was Diabetes mellites. There was no difference in the proportion of diabetic kidney disease, contrary to that noted in some of the earlier reports. Previous studies done in India have shown difference in aetiology between private and government sectors. Previously Diabetes was the most common cause in Private and Chronic Glomerulonephritis was the most common cause in Government hospitals. However, in our study done in a Government hospital Diabetes Mellites is the most common cause. This illustrates the Global Diabetes Pandemic becoming the most common cause of ESRD in all areas irrespective of urban or rural 
difference. ${ }^{[4,5,6,7 .]}$ According to data from the US Renal Data System 2014 cited by National Centre for Chronic Disease Prevention and Health Promotion, the primary causes of ESRD in the United States were diabetes ( $44 \%$ of cases in 2014 and $37.47 \%$ of cases in 2015) followed by hypertension(29\% of cases in 2014 and $25.1 \%$ cases in 2015) ${ }^{[8]}$.

More than ninety-seven patients have had emergency Haemodialysis initiation through Internal Jugular vein cannulation. This would result in more prolonged hospital stay and consumption of expenses for the caretaker. Moreover, late presentation results in catastrophic "out of pocket" expenditure pushing many already poor families into abject poverty. The greater number of Haemodialysis initiated through the Venous catheters would result in increased occurrence of catheter related blood stream infection and sepsis and malnutrition which contributes to the decrease in functional status of the patient. ${ }^{[9,10]}$

In our study the mean platelet count of all patients was 1.86 lakhs. This is in accordance with the review by review by Algirdas et al which stated that platelet number was potentially reduced in haemodialysis patients to the range of 1.75-1.80 lakhs ${ }^{[11 .]}$ In our study serum total protein was 6.6 $\mathrm{g} / \mathrm{dl}$. However, studies have suggested that plasma protein should be used as a single criterion for nutritional status, due to other contributing factors including age, comorbidities, hypervolemia, and weight $\operatorname{loss}^{[12]}$. The mean SGOT and SGPT were in normal value ranges a result supported by Hou et al.who reported that there was no observed impairment in the liver function of haemodialysis patients ${ }^{[13]}$.The mean potassium level of all patients in this study was less than $4 \mathrm{me} / \mathrm{L}$ (3.72meq/L; SD 0.84), a study by Kirtankar et al. reported that serum potassium levels of 3.5-4 meq/L could be associated with higher risk of mortality. The mean sodium level of all patients in this study was 134 meq/l (SD 4.9); low sodium levels were associated with higher risk of mortality according to a study by Sun et al. ${ }^{[14]}$
In the western world most patients receive thrice weekly haemodialysis whereas in India many patients receive twice weekly haemodialysis. The reason being difficulty in access for thrice weekly haemodialysis. According to Fernandez et al. the clinical profile is better among patients who received twice-weekly HD without adjustment for residual kidney function. In our study on comparing patients receiving twice weekly haemodialysis with thrice weekly haemodialysis, the dialysis vintage was longer and inter dialytic weight gain was lower in in those receiving thrice weekly hemodialysis. There was no difference in the laboratory profile except for platelet count and serum sodium. ${ }^{[15,16]}$.

\section{Strengths and Limitations of This Study}

A limitation of this study was the cross-sectional design, which did not explain the causal relationships among two or more variables but showed only the association of the variables. Residual Renal function was not measured. However, this study presented not only the epidemiological profiles but also the laboratory results from a major government teaching hospital in south India.

\section{Conclusions}

Patients with ESRD undergoing haemodialysis were mostly middle-aged males who were unemployed and married. Diabetes was the most common aetiology in these populations. Vascular access was most frequently achieved via the AV fistula. In addition, most of the patients had dialysis initiated through a central venous access. The mean albumin, calcium, levels of participants were in the normal range, while the mean levels of haemoglobin was lower than normal values. There was no significant difference in comparing patients undergoing twice weekly haemodialysis with thrice weekly haemodialysis except for longer dialysis vintage, lower inter dialytic weight gain, higher platelet count and higher serum sodium levels. 


\section{Acknowledgements}

We would like to appreciate the medical staffs of Haemodialysis Unit at Kanyakumari Government Medical College Hospital for their cooperation during this study.

\section{References}

1. Hill NR, Fatoba ST, Oke JL, Hirst JA, O'Callaghan CA, Lasserson DS, et al. Global prevalence of chronic kidney disease - a systematic review and metaanalysis. PLOS ONE. 2016;11:e0158765.

2. Lijie M, Sumei Z. Risk factors for mortality in patients undergoing hemodialysis: a systematic review and meta-analysis. Int J Cardiol. 2017;238:151-8.

3. Vijayalaksmi UB, Rayidi M. Laboratory Profiles of Patients on hemodialysis - a retrospective one year study in a rural tertiaty care hospital. J Clin Diagn Res. 2015;9:12-5.

4. Mani MK: Chronic renal failure in India. Nephrol Dial Transplant 1993,8(8):684689.

5. Mittal S, Kher V, Gulati S, Agarwal LK, Arora P: Chronic renal failure in India. Ren Fail 1997, 19(6):763-770.

6. Agarwal SK, Dash SC: Spectrum of renal diseases in Indian adults. J Asso Physicians India 2000, 48(6):594-600.

7. Sakhuja V, Jha V, Ghosh AK, Ahmed S, Saha TK: Chronic renal failure in India. Nephrol Dial Transplant 1994, 9(7):871872

8. National Center for Chronic Disease Prevention and Health Promotion. National chronic kidney disease fact sheet, 2017. http://www.cdc.gov/kidneydisease/ pdf/kidney_factsheet.pdf (2017).

9. Parameswaran S, Geda SB, Rathi M, Kohli HS, Gupta KL, Sakhuja V, Jha V: Referral pattern of end-stage renal disease patients and its impact on outcome at a public sector hospital. Natl Med J India 2011, 24(4):208-213.

10. Rajapurkar et al. What do we know about chronic kidney disease in India: first report of the Indian CKD registry BMC Nephrology 2012, 13:10

11. Daugirdas JT, Bernardo AA. Hemodialysis effect on platelet count and function and hemodialysis-associated thrombocytopenia. Kidney Int. 2012;82:147-57

12. Fan F, Jia J, Li J, Huo Y, Zhang Y. White blood cell count predicts the odds of kidney function decline in a Chinese community-based population. BMC Nephrol. 2017;18:190]

13. Hou YC, Liu WC, Liao MT, Lu KC, Lo L, Pan HC, et al. Long-term and short-term effects of hemodialysis on liver function evaluated using the galactose single-point test. Scientific World Journal. 2014;2014:260939.

14. Korgaonkar S, Tilea A, Gillespie BW, Kiser M, Eisele G, Finkelstein F et al. Serum potassium and outcomes in CKD: insights from the RRI-CKD cohort study. Clin J Am Soc Nephrol. 2010;5:762-9

15. Fernández-Lucas M, Teruel-Briones JL, Gomis-Couto A, Villacorta-Pérez J, Quereda-Rodríguez Navarro C. Maintaining residual renal function in patients on haemodialysis: 5-year experience using a progressively increasing dialysis regimen. Nefrologia. 2012; 32:767-776.

16. Hanson JA, Hulbert-Shearon TE, Ojo AO, Port FK, Wolfe RA, Agodoa LY, Daugirdas JT. Prescription of twiceweekly hemodialysis in the USA. Am J Nephrol. 1999; 19:625-633. 